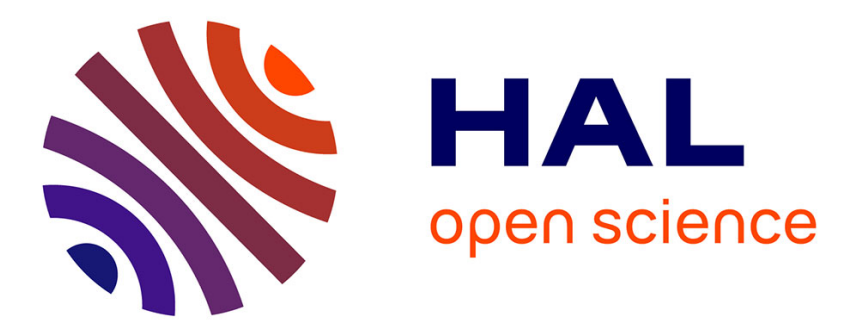

\title{
Trends in return to work of breast cancer survivors
} C. A. M. Roelen, P. C. Koopmans, W. Rhenen, J. W. Groothoff, J. J. L. Klink, U. Bültmann

\section{To cite this version:}

C. A. M. Roelen, P. C. Koopmans, W. Rhenen, J. W. Groothoff, J. J. L. Klink, et al.. Trends in return to work of breast cancer survivors. Breast Cancer Research and Treatment, 2011, 128 (1), pp.237-242. 10.1007/s10549-010-1330-0 . hal-00615394

\section{HAL Id: hal-00615394 \\ https://hal.science/hal-00615394}

Submitted on 19 Aug 2011

HAL is a multi-disciplinary open access archive for the deposit and dissemination of scientific research documents, whether they are published or not. The documents may come from teaching and research institutions in France or abroad, or from public or private research centers.
L'archive ouverte pluridisciplinaire HAL, est destinée au dépôt et à la diffusion de documents scientifiques de niveau recherche, publiés ou non, émanant des établissements d'enseignement et de recherche français ou étrangers, des laboratoires publics ou privés. 


\section{Trends in return to work of breast cancer survivors}

C.A.M. Roelen, P.C. Koopmans, W. van Rhenen, J.W. Groothoff, J.J.L. van der Klink, U. Bültmann

Corné AM Roelen, MD PhD; Department of Health Sciences, University Medical Center Groningen, University of Groningen, PO Box 196, 9700 AD Groningen, the Netherlands; ArboNed Corporate Accounts, PO Box 158, 8000 AD Zwolle, the Netherlands.

Petra C Koopmans, PhD; ArboNed Statistics, PO Box 141, 9700 AC Groningen, the Netherlands. Willem van Rhenen, MD PhD; professor of Engagement and Productivity, Center for Human Resource, Organization and Management Effectiveness, Business University Nyenrode, PO Box 130, 3620 AC Breukelen; ArboNed Occupational Health Services, PO Box 850913508 AB Utrecht, the Netherlands.

Johan W Groothoff PhD; professor of Work \& Health, Department of Health Sciences, University Medical Center Groningen, University of Groningen, PO Box 196, 9700 AD Groningen, the Netherlands.

Jac J L van der Klink, MD, PhD; professor of Social Medicine, Department of Health Sciences, University Medical Center Groningen, University of Groningen, PO Box 196, 9700 AD Groningen, the Netherlands.

Ute Bültmann PhD, Department of Health Sciences, University Medical Center Groningen, University of Groningen, PO Box 196, 9700 AD Groningen, the Netherlands.

\section{Corresponding author:}

Corné A.M. Roelen, ArboNed Corporate Accounts, PO Box 158, 8000 AD Zwolle.

Telephone +3138 4554700, telefax +3138 4537272; e-mail: corne.roelen@ arboned.nl 
Purpose: Most women interrupt their work activities during the treatment of cancer. This study investigated return to work (RTW) after treatment of breast cancer in the period from January 2002 to December 2008.

Methods: ArboNed Occupational Health Services records the sickness absence and RTW data of more than one million workers of whom approximately $40 \%$ are women. Incident cases of sickness absence due to breast cancer (ICD-10 code C50) were selected from the ArboNed register. Proportions of partial RTW, with $50 \%$ of the earnings before sickness absence, and full RTW were determined one year after diagnosis. Trends in partial RTW and full RTW were examined by Chi-square trend analysis. The time to partial RTW and full RTW was analysed by Cox regression and stratified by age ( $<40$ years, $40-50$ years and $>50$ years).

Results: The proportion of partial RTW was stable around 70\% from 2002 to 2008 . The proportion of full RTW decreased from 52\% in 2002 to $43 \%$ in 2008 and showed a linear decline in women of all ages. The time to partial RTW and full RTW in the years 2003 to 2008 did not change significantly compared with 2002 .

Conclusions: In the Netherlands, the proportion of employed women who fully resumed working after breast cancer within one year of diagnosis has decreased since 2002. These results warrant more epidemiological research to examine the trends in RTW of breast cancer survivors across countries.

Key words: sick leave; breast cancer; return to work; epidemiology 
Breast cancer is the most common malignancy in women of working ages. The majority of women survive because they are diagnosed with early-stage disease and receive a treatment that is focused on curing breast cancer and preventing relapse of disease. The age-adjusted five-year survival varies between European countries from 70\% in the Czech Republic and Poland to more than $80 \%$ in the Scandinavian countries and the survival rates are increasing [1]. In the Netherlands, the five-year survival after breast cancer was $77 \%$ in $1998,81 \%$ in 2003 and $85 \%$ in 2008 [2, 3]. Employed women usually interrupt their work for the treatment of breast cancer. Prolonged sickness absence often generates loss of income and social exclusion. Therefore, return to work (RTW) during or after breast cancer treatment is important, all the more because RTW restores social relations and participation, which adds to the patient's quality of life [4-6].

RTW after breast cancer has been studied in different countries with different jurisdictions. In a prospective multicenter study from 1990 to 1994 including research groups from the UK, Sweden and Italy, it was reported that $79 \%$ of premenopausal women had returned to work 12 months after the diagnosis of breast cancer and $86 \%$ within 36 months of diagnosis [7]. In a Canadian study, $71 \%$ of women diagnosed with breast cancer in 1996-1997 resumed work within 12 months of diagnosis and $89 \%$ within 36 months [8]. In 2001-2002, 82\% of American women had returned to work 18 months after the diagnosis of breast cancer [9]. Recent European studies reported lower percentages of women resuming work after breast cancer. For example, Johnsson et al. (2009) found that 59\% of 102 Swedish women had returned to work within 10 months of surgery for primary early-stage breast cancer [10]. Fantoni et al. (2010) found that $54 \%$ of 379 women diagnosed with breast cancer in 20042005 in France resumed work within 12 months after starting cancer treatment [11]. The different RTW rates may be explained by differences in health care systems and social insurances across countries $[12,13]$. In the Netherlands, for example, sickness absence is usually fully compensated by the employer in the first year and up to $70 \%$ in the second year, irrespective of the cause of sickness absence. Thus, not only work-related injuries are compensated, but also non work-related disorders such as breast cancer. 
While between 2001 and 2005, 63\% of employed Dutch women diagnosed with breast cancer returned to work within 12 months of diagnosis [14], 54\% resumed work within 12 months of diagnosis between 2004 and 2007 [15]. This may indicate a decrease in RTW of breast cancer survivors. Therefore, the present descriptive epidemiological study investigated the trends in the proportions and time to RTW of women diagnosed with breast cancer in the period from 2002 to 2008.

\section{METHOD}

\section{Study setting and population}

ArboNed Occupational Health Services contracts more than 33,000 companies of different economic sectors in the Netherlands to provide employees with occupational health care. ArboNed registers the sickness absence and RTW data of more than 1 million employees working in these contracted companies. Sickness absence is medically certified by an occupational physician (OP) within six weeks of reporting sick. The cause of sickness absence is recorded by the OP according to the World Health Organization's $10^{\text {th }}$ International Classification of Diseases (ICD-10). For this study, incident cases of sickness absence due to OP-certified breast cancer (ICD-10 C50) were selected from the ArboNed register in the period from January 2002 to December 2008. Men who were diagnosed with breast cancer and women with recurrent breast cancer were excluded from analysis as RTW trends in these cases may differ from the trends in primary breast cancer among women.

\section{Ethical considerations}

Ethical approval was not required because the Act on Scientific Medical Research does not apply to the analysis of register data without involving the employees themselves [16]. All employees consented to the analysis of their sickness absence data when data were registered.

\section{Data analysis}

The sickness absence data were retrieved from the ArboNed sickness absence register. Partial RTW was defined as RTW with $50 \%$ of the earnings before sickness absence for at least 28 consecutive 
days. Full RTW was defined as RTW with $100 \%$ of the earnings before sickness absence for $\geq 28$ consecutive days. Proportions of women with partial RTW and full RTW were analysed one year after reporting sick with breast cancer. Trends in the proportions of partial and full RTW were investigated by Chi-square analysis for linear trends stratified by age ( $<40$ years, $40-50$ years and $>50$ years).

The time to partial RTW was examined by Cox proportional hazards regression analysis stratifying for age $<40$ years, $40-50$ years, and $>50$ years. Likewise, the time to full RTW was investigated in a separate Cox regression model. Hazard ratios (HR) relative to RTW in 2002 and their $95 \%$ confidence intervals (CI) were calculated with $\mathrm{HR}<1.0$ reflecting a longer time to RTW relative to 2002 and HR>1.0 a shorter time to RTW relative to 2002 .

All statistical analyses were performed in SPSS for Windows version 16 and statistical significance was set at the $5 \%$ level $(\alpha=0.05)$.

\section{RESULTS}

The incidence of primary breast cancer increased from 101 per 100,000 employed women in 2002 to 124 per 100,000 employed women in 2008, which is in line with the Dutch population incidence of 129 per 100,000 women in 2008. The numbers and age distribution of all employed women and the selected breast cancer cases are presented in Table 1.

[insert Table 1 about here]

\section{Proportion of RTW}

In the period from 2002 to 2008 , the proportion of partial RTW was $65-76 \%$ in women aged $<40$ years, $66-75 \%$ in women aged $40-50$ years, and $68-79 \%$ in women aged $>50$ years. Among women aged $>50$ years at diagnosis there was a declining trend $\left(\chi^{2}\right.$ for linear trends $\left.\mathrm{P}=0.037\right)$ in the proportion of partial RTW from 79\% in 2003 to $68 \%$ in 2008 (Figure 1). The proportion of partial RTW increased non-significantly ( $\mathrm{P}=0.074)$ from 66\% in 2002 to $74 \%$ in 2008 among women who were diagnosed with breast cancer between 40 and 50 years of age. 
In 2002, 52\% of women had full RTW within one year of reporting sick with breast cancer as compared to $43 \%$ in 2008. Figure 1 shows linear declining trends in the proportion of full RTW in women of all ages. Full RTW in women $<40$ years decreased from 55\% in 2002 to $40 \%$ in 2008 ( $\chi^{2}$ for linear trends $\mathrm{P}=0.003$ ). In women aged 40-50 years, full RTW decreased from $46 \%$ in 2002 to $41 \%$ in $2008(\mathrm{P}=0.042)$, and in women $>50$ years from $59 \%$ to $46 \%(\mathrm{P}=0.001)$.

[insert figure 1 about here]

\section{Time to RTW}

The median time to partial RTW was 294 days in 2002 and 282 days in 2008. The time to partial RTW did not change significantly over the years compared with 2002 (Table 2). As is shown in Table 3, the median time to full RTW did not change over the years either, although the overall median time to full RTW was borderline significantly ( $\mathrm{p}=0.05$ ) longer in 2008 compared with 2002.

[insert Tables 2 and 3 about here]

\section{DISCUSSION}

Partial RTW one year after the diagnosis of breast cancer was more or less stable around $70 \%$ in the period from 2002 to 2008, whereas full RTW showed a decreasing trend in women of all ages.

The strength of our study is that it covered a large population of employees working in different economic sectors. Studying registered sickness absence eliminates the recall bias that affects selfreported sickness absence $[17,18]$. The sickness absence register study could be performed quickly and inexpensively without the need to involve the employees themselves. The main limitation, however, was that the number of variables available from the sickness absence register was limited. For example, information about work accommodations or placement in another job was not recorded in the register. Furthermore, we had no access to the medical files of the patients. Hence, information on the stage of breast cancer (local, regional or metastatic), type of treatment, and persisting limitations and symptoms such as fatigue [19-22], distress [23, 24] and depressive symptoms [21, 
25] was not available.

The fact that the sickness absence register contained a limited number of variables impeded the interpretation of the results. Therefore, the decreasing proportions of full RTW can not be explained robustly. It is possible that the decreasing proportion of RTW is the result of a change in Dutch disability policies in 2004. Before 2004, sickness absence was compensated by employers for a period of one year, and since 2004 sickness absence compensation is granted for a period of two years. However, if policy changes were responsible for the decrease in full RTW, then one would also expect a decline in partial RTW, which was not found.

An alternative explanation for the decreasing proportions of RTW one year after the diagnosis of breast cancer may be the broadened indication for chemotherapy in the Netherlands among young breast cancer survivors [26]. It has been recognized that women who are treated with chemotherapy are less likely to resume their work [7, 9-11, 22, 27, 28]. As chemotherapy delays RTW, one would expect a longer time to partial RTW if the decreasing proportion of full RTW after breast cancer is the result of a more sophisticated adjuvant treatment. The study showed, however, that the time to RTW did not change significantly over the years. Thus, women resume work initially, but it is possible that full RTW is impeded by symptoms persisting after the treatment of breast cancer. Hansen et al. (2008) reported that fatigue was most strongly related to work limitations and explained $71 \%$ of the symptom burden of employees after the diagnosis of breast cancer [21]. Calvio et al. (2010) reported that the symptom burden reduced the performance-based work output of breast cancer survivors. They also showed that breast cancer survivors experienced cognitive difficulties, particularly due to deficits in memory and executive function [24], while work is becoming more and more mentally demanding [29]. Although the level of job control in the Netherlands is relatively high, work pace and work pressure are increasing and cancer survivors may feel distressed that they are not able to perform at their pre-diagnosis level [5]. Therfore, women experiencing fatigue, distress and cognitive difficulties may be uncertain to fully resume their work. 
Another explanation for the decline in full RTW after breast cancer may be that attitudes towards work have changed after cancer. Breast cancer survivors may put less value on work and for half of them financial pressure was the primary reason for resuming work [5]. Tiedtke et al. (2010) reviewed articles published between 1995 and 2008 on the experiences of breast cancer survivors with RTW [30]. The authors found that women altered their work priorities and ambitions, which was reported by Maunsell et al. (2004) as one of the reasons for stopping work after breast cancer [31].

Finally, it is important to notice that breast cancer survivors receive little advice about returning to work [30]. Work issues were scarcely discussed with treating physicians and in many cases company physicians or insurance physicians followed the patient's wishes, letting them decide for themselves about resuming work [5]. Uncertainty about work ability after treatment and mixed feelings about the work environment may be barriers in the RTW process. A guideline has been developed for Dutch OPs to support cancer survivors in RTW [32]. This guideline accentuates the importance of advising cancer patients about their RTW, taking the influence of physical and psychological limitations on the patient's work ability into account. Implementation of this guideline in daily occupational health practice may improve RTW of cancer survivors in the years to come.

In conclusion, the proportion of women who resume working after breast cancer has decreased in the Netherlands over the period from 2002 to 2008. This warrants more epidemiological research on the trends in RTW in breast cancer survivors across countries. In this study, follow-up of breast cancer survivors was restricted to one year and longer follow-up is needed to provide insight in sustained work beyond one year of diagnosis.

\section{CONFLICT OF INTEREST}

All authors state that they have no financial or other conflicts of interest that might bias their work and contribution to this paper. 


\section{REFERENCES}

1. Eurocare: http://www.eurocare.it/Results/tabid/79/Default.aspx. Accessed 10 October 10 2010.

2. http://www.ikcnet.nl/nieuws/index.php?id=5418. Accessed 15 August 2010.

3. http://www.ikcnet.nl/uploaded/FILES/Landelijk/cijfers/overleving/7.xls. Accessed 15 August 2010.

4. Ganz PA, Coscarelli A, Fred C, Kahn B, Polinsky ML, Petersen L (1996) Breast cancer survivors: psychosocial concerns and quality of life. Breast Cancer Res Treat 38:183-199.

5. Kennedy F, Haslam C, Munir F, Pryce J (2007) Returning to work following cancer: a qualitative exploratory study into the experience of returning to work following cancer. Eur J Cancer Care 16:17-25.

6. Groenvold M (2010). Health-related quality of life in early breast cancer. Dan Med Bull $57: B 4184$

7. Johnsson A, Fornander T, Olsson M, Nystedt M, Johansson H, Rutqvist LE (2007) Factors associated with return to work after breast cancer treatment. Acta Oncol 46:90-96.

8. Drolet M, Maunsell E, Mondor M, Brisson C, Brisson J, Mâsse B, Deschênes L (2005) Work absence after breast cancer diagnosis: a population-based study. CMAJ 173:765-771.

9. Bouknight RR, Bradley CJ, Luo Z (2006) Correlates of return to work for breast cancer survivors. J Clin Oncol 24:345-353.

10. Johnsson A, Fornander T, Rutqvist LE, Vaez M, Alexanderson K, Olsson M (2009) Predictors of return to work ten months after primary breast cancer surgery. Acta Oncol 48:93-98.

11. Fantoni SQ, Peugniez C, Duhamel A, Skrzypczak J, Frimat P, Leroyer A (2010) Factors related to return to work by women with breast cancer in Northern France. J Occup Rehabil 20:49-58.

12. Snashall D (2008) Health of the working age population. New report recommends integration of occupational health into mainstream healthcare. BMJ 336:682. 
13. Bloch FS, Prins R (2001) Who returns to work and why ? A six country study on work incapacity and integration. International Social Security Series, volume 5. Transaction Publishers, London.

14. Roelen CA, Koopmans PC, Graaf JH de, Balak F, Groothoff JW (2009) Sickness absence and return to work rates in women with breast cancer. Int Arch Occup Environ Health 82:443-446.

15. Roelen CA, Koopmans PC, Groothoff JW, Klink JJ van der, Bültmann U (2010) Sickness absence and full return to work after cancer: two year follow-up of register data for different cancer sites. Psychooncology. DOI: 10.1002/pon.1820.

16. KNAW (2003) Guidelines for the use of personal data in scientific research [in Dutch]. Social Scientific Board, Amsterdam.

17. Van Poppel M, de Vet H, Koes B, Smid T, Bouter L (2002) Measuring sick leave: a comparison of self-reported data on sick leave and data from company records. Occup Med $52: 485-490$.

18. Voss M, Stark S, Alfredsson L, Vingård E, Josephson M (2008) Comparisons of self-reported and register data on sickness absence among public employees in Sweden. Occup Environ Med 65:61-67.

19. Spelten ER, Verbeek JAHM, Uitterhoeve ALJ, et al. (2003) Cancer, fatigue and the return of patients to work - a prospective cohort study. Eur J Cancer 39:1562-1567.

20. Bower JE, Ganz PA, Desmond KA, et al. (2006) Fatigue in long-term breast cancer survivors. Cancer 106:751-758.

21. Hansen JA, Feuerstein M, Calvio LC, Olsen CH (2008) Breast cancer survivors at work. J Occup Environ Med 50: 777-784.

22. Ahn E, Cho J, Shin DW, Park BW, Ahn SH, Dong-Young N, Nam SJ, Lee ES, Yun YH (2009) Impact of breast cancer diagnosis and treatment on work-related life and factors affecting them. Breast Cancer Res Treat 116: 609-616.

23. Henselmans I, Helgeson VS, Seltman H, de Vries J, Sanderman R, Ranchor AV (2010) Identification and prediction of distress trajectories in the first year after a breast cancer diagnosis. Health Psychol 29:160-168. 
24. Calvio L, Peugeot M, Burns GL, Todd BL, Feuerstein M (2010). Measures of cognitive function and work in occupationally active breast cancer survivors. J Occup Environ Med 52: 219-227.

25. Reich M, Lesur A, Perdrizet-Chevallier C (2008) Depression, quality of life and breast cancer: a review of the literature. Breast Cancer 110:9-17.

26. Sukel MP, van de Poll-Franse LV, Nieuwenhuijzen GA et al. (2008) Substantial increase in the use of adjuvant systemic treatment for early stage breast cancer reflects changes in guidelines in the period 1990-2006 in the southeastern Netherlands. Eur J Cancer 44:18461854.

27. Balak F, Roelen CA, Koopmans PC, ten Berge EE, Groothoff JW (2008) Return to work after early-stage breast cancer: a cohort study into the effects of treatment and cancer-related symptoms. J Occup Rehabil 18:267-272.

28. De Boer AG, Verbeek JH, Spelten ER, et al. (2008) Work ability and return to work in cancer patients. Br J Cancer 98: 1342-1347.

29. Van Hooff M, van den Bossche S, Sumlders P (2008) The Netherlands Working Conditions Survey. http://www.tno.nl/downloads/TNO-KvL_NEA_Brochure_2007_Eng.pdf.

30. Tiedtke C, de Rijk A, Dierckx de Casterlé B, Christaens M-R, Donceel P (2010) Experiences and concerns about 'returning to work' for women breast cancer survivors: a literature review. Psychooncology 19: 677-682.

31. Maunsell E, Drolet M, Brisson J, Brisson C, Mâsse B, Deschênes L (2004) Work situation after breast cancer : results from a population-based study. J Natl Cancer Inst 96: 1813-1821.

32. Netherlands Society of Occupational Medicine (2009) Cancer and Work [in Dutch]. http://nvab.artsennet.nl/Artikel-3/Blauwdruk-Kanker-en-Werk.htm. 

TABLE 1 Study population stratified by age

\begin{tabular}{|c|c|c|c|c|c|c|c|}
\hline & 2002 & 2003 & 2004 & 2005 & 2006 & 2007 & 2008 \\
\hline Total number of employees & $1,011,555$ & 986,340 & $1,091,578$ & $1,010,686$ & $1,024,100$ & 972,758 & $1,012,345$ \\
\hline Number of women & 395,275 & 391,239 & 438,115 & 410,528 & 419,253 & 379,175 & 397,731 \\
\hline$<40$ years & 221,722 & 214,146 & 234,755 & 216,659 & 215,707 & 200,967 & 207,031 \\
\hline $40-50$ years & 108,992 & 111,299 & 125,108 & 117,753 & 121,751 & 101,814 & 108,644 \\
\hline$>50$ years & 64,561 & 65,794 & 78,252 & 76,116 & 81,795 & 76,394 & 82,056 \\
\hline Incident breast cancer cases & $398(1.0 \%)$ & $499(1.3 \%)$ & $532(1.2 \%)$ & $494(1.2 \%)$ & $507(1.2 \%)$ & $435(1.1 \% 0)$ & $492(1.2 \% 0)$ \\
\hline$<40$ years & 88 & 89 & 99 & 102 & 70 & 60 & 76 \\
\hline $40-50$ years & 175 & 235 & 234 & 211 & 252 & 211 & 212 \\
\hline$>50$ years & 135 & 175 & 199 & 181 & 185 & 164 & 204 \\
\hline
\end{tabular}


TABLE 2 Partial return to work with $50 \%$ of the earnings before sickness absence within one year of breast cancer diagnosis

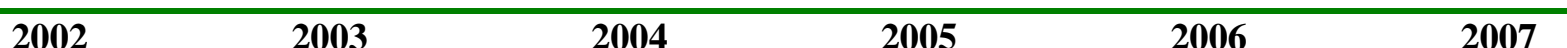

2008

\begin{tabular}{|c|c|c|c|c|c|c|c|}
\hline \multicolumn{8}{|l|}{ Duration to partial RTW } \\
\hline Median $\left(95 \% \mathrm{CI}^{\mathrm{a}}\right)$ days & $294(261-327)$ & $259(235-283)$ & $269(244-294)$ & $274(241-307)$ & $290(258-322)$ & $280(252-308)$ & $282(247-317)$ \\
\hline$<40$ years & $295(228-362)$ & $283(231-335)$ & $286(226-346)$ & $249(123-375)$ & $298(170-426)$ & $287(206-368)$ & $321(282-360)$ \\
\hline $40-50$ years & $329(283-375)$ & $301(256-346)$ & $276(241-311)$ & $312(264-360)$ & $290(257-323)$ & $294(261-327)$ & $280(241-319)$ \\
\hline$>50$ years & $256(218-294)$ & $215(184-246)$ & $257(218-296)$ & $250(208-292)$ & $277(219-335)$ & $252(197-307)$ & $287(224-350)$ \\
\hline \multicolumn{8}{|l|}{ Time to partial RTW } \\
\hline \multirow[t]{4}{*}{$\mathrm{HR}^{\mathrm{b}}\left(95 \% \mathrm{CI}^{\mathrm{a}}\right)$} & 1.00 & $1.10(0.94-1.29)$ & $1.13(0.97-1.32)$ & $1.09(0.93-1.27)$ & $1.09(0.93-1.27)$ & $1.08(0.92-1.27)$ & $1.08(0.92-1.26)$ \\
\hline & 1.00 & $1.04(0.73-1.47)$ & $1.01(0.72-1.42)$ & $1.04(0.74-1.46)$ & $0.97(0.67-1.40)$ & $0.93(0.62-1.39)$ & $0.93(0.65-1.35)$ \\
\hline & 1.00 & $1.07(0.84-1.36)$ & $1.30(1.03-1.65)$ & $1.08(0.84-1.37)$ & $1.22(0.97-1.54)$ & $1.19(0.93-1.51)$ & $1.31(1.03-1.67)$ \\
\hline & 1.00 & $1.22(0.94-1.58)$ & $1.00(0.78-1.30)$ & $1.11(0.85-1.43)$ & $1.01(0.78-1.31)$ & $1.03(0.79-1.34)$ & $0.91(0.71-1.18)$ \\
\hline
\end{tabular}

${ }^{\mathrm{a}} \mathrm{CI}=$ confidence interval

${ }^{\mathrm{b}} \mathrm{HR}=$ hazard ratio; a HR<1.0 reflects a longer time to RTW relative to 2002 and a HR>1.0 indicates a shorter time to RTW relative to 2002 
TABLE 3 Full return to work with $100 \%$ of the earnings before sickness absence within one year of breast cancer diagnosis

$\begin{array}{lllllll}2002 & 2003 & 2004 & 2005 & 2006 & 2007 & 2008\end{array}$

\begin{tabular}{|c|c|c|c|c|c|c|c|}
\hline Duration to full RTW & & & & & & & \\
\hline Median $\left(95 \% \mathrm{CI}^{\mathrm{a}}\right)$ days & $351(338-364)$ & $340(318-362)$ & $334(311-357)$ & $353(332-374)$ & $373(346-400)$ & $371(345-397)$ & $390(358-422)$ \\
\hline$<40$ years & $350(303-397)$ & $340(306-374)$ & $364(289-439)$ & $351(252-450)$ & $430(318-542)$ & $424(358-490)$ & $460(367-553)$ \\
\hline $40-50$ years & $365(358-372)$ & $364(357-371)$ & $338(301-375)$ & $382(340-424)$ & $398(361-435)$ & $378(341-415)$ & $393(362-424)$ \\
\hline$>50$ years & 323 (269-377) & $281(244-318)$ & $322(285-359)$ & $324(289-359)$ & $341(310-372)$ & $348(303-393)$ & $365(308-422)$ \\
\hline Time to full RTW & & & & & & & \\
\hline $\mathrm{HR}^{\mathrm{b}}\left(95 \% \mathrm{CI}^{\mathrm{a}}\right)$ & 1.00 & $1.07(0.89-1.28)$ & $1.10(0.92-1.32)$ & $1.01(0.84-1.22)$ & $0.88(0.73-1.06)$ & $0.87(0.71-1.05)$ & $0.83(0.68-1.00)$ \\
\hline$<40$ years & 1.00 & $1.00(0.67-1.49)$ & $0.88(0.59-1.32)$ & $1.02(0.69-1.51)$ & $0.72(0.45-1.14)$ & $0.61(0.37-1.02)$ & $0.67(0.42-1.06)$ \\
\hline $40-50$ years & 1.00 & $1.08(0.81-1.43)$ & $1.33(1.00-1.76)$ & $1.02(0.76-1.37)$ & $0.95(0.71-1.27)$ & $0.96(0.71-1.29)$ & $0.93(0.69-1.26)$ \\
\hline$>50$ years & 1.00 & $1.14(0.85-1.52)$ & $0.99(0.75-1.32)$ & $0.99(0.74-1.33)$ & $0.89(0.66-1.20)$ & $0.88(0.65-1.20)$ & $0.79(0.59-1.07)$ \\
\hline
\end{tabular}

\footnotetext{
${ }^{\mathrm{a}} \mathrm{CI}=$ confidence interval

${ }^{\mathrm{b}} \mathrm{HR}=$ hazard ratio; a HR<1.0 reflects a longer time to RTW relative to 2002 and a HR $>1.0$ indicates a shorter time to RTW relative to 2002
} 

Figure 1 Trends in return to work (RTW) after the diagnosis of breast cancer from 2002 to 2008

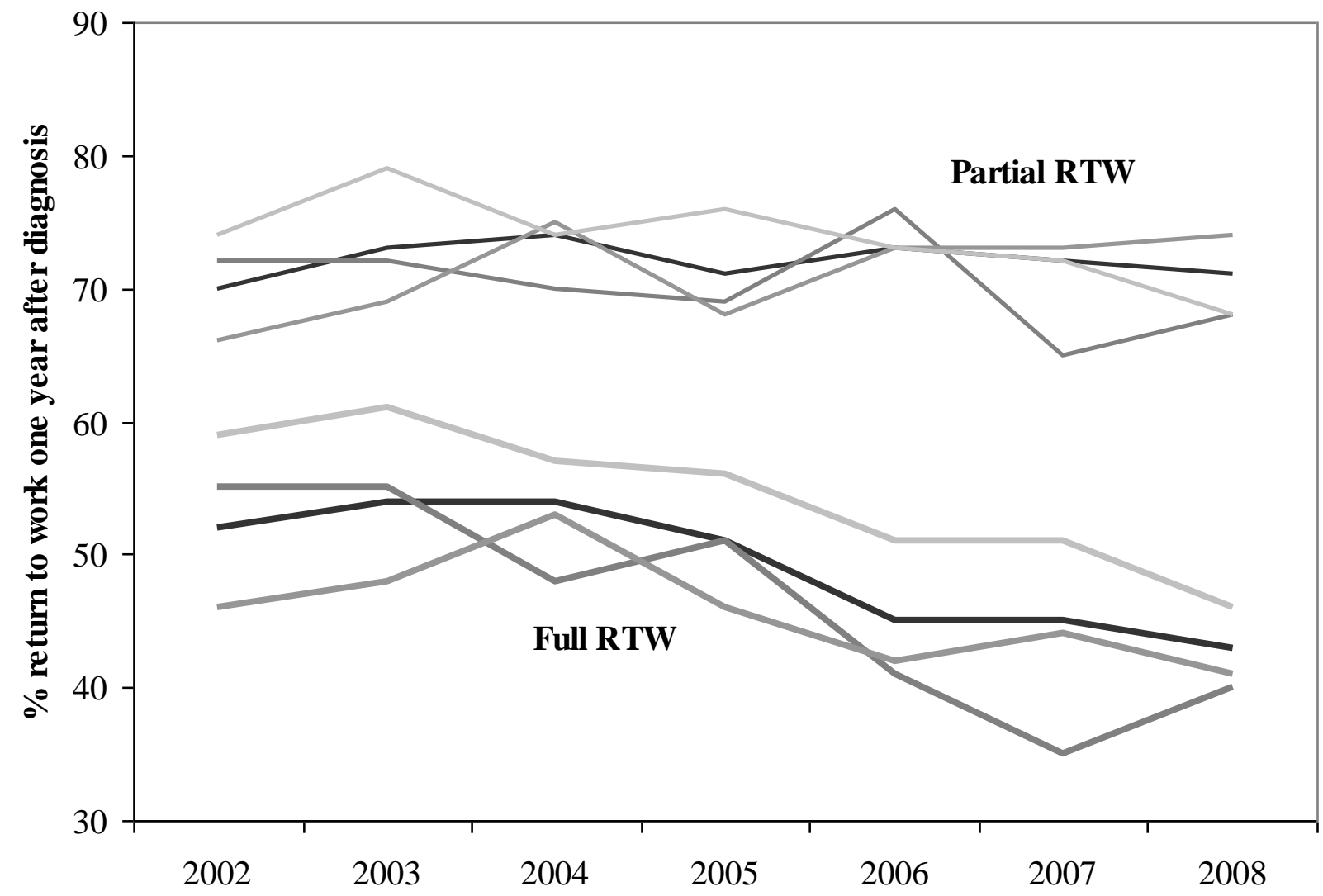

The figure shows the percentages of RTW within one year of diagnosis of breast cancer in women aged $<40$ years (dark grey lines), 40-50 years (medium grey lines) and $>50$ years (light grey lines); the black lines reflect the overall RTW percentages one year after diagnosis. 